lined the so-called crevasse entry technique and showed its corresponding impact on design of r.f. bridges.

In describing a technique for measurement of impedance within a micro-circuit module, authors from the University of Southampton showed how they had been able to achieve a satisfactory connexion between circuit and measuring bridge by use of a micro-strip line. Certain authors chose to support their papers by practical demonstrations of relevant equipment. It was interesting, after a paper on attenuation measurement, to see Russian and American standard attenuation measuring equipment compared side by side.

Whilst the conference succeeded in its prime aim of highlighting British work on r.f. measurements, it must be regretted that no corresponding European contribution was forthcoming.

\section{New Way of Looking at Plants}

THE scanning electron microscope, with its wide depth of field giving almost three-dimensional pictures, is clearly going to be very useful to botanists. At the meeting of the Linnean Society on November 16, Dr P. Echlin described some of the techniques being developed for use with this microscope, and Professor V. H. Heywood showed how these techniques can be particularly valuable to the taxonomist.

The advantage of the machine is that whole specimens can be viewed rather than the sections which are necessary with the transmission electron microscope. Dr Echlin and his colleagues at the University of Cambridge are looking for the best ways of fixing the specimens, which he had classified as robust dry, robust wet and labile. Robust dry specimens, such as pollen. grains, seeds and fruits, can be glued directly on to a clean surface. Dust, which will show up in the pictures, is a considerable problem, and at Cambridge a vacuum pump is used as a mini-vacuum cleaner to keep specimens as clean as possible. The robust wet specimens, which include diatoms and some algae and microfossils, can be placed without glue on to a surface and dried in a dust free atmosphere. Labile specimens present most problems, and although they can be dried by more conventional methods, such as passage through a series of alcohols, freeze drying has proved the most successful. Dr Echlin has developed a technique which involves dipping specimens into isopentane or 'Freon 22' cooled in liquid nitrogen. Using this technique, Chlorella can be fixed without collapsing, as it does when dried by more conventional methods. Blue-green algae and bacteria are also successfully. fixed in this way.

Although the scanning electron microscope can give little information that cannot be obtained from serial sections in the transmission version, the use of whole specimens makes investigation very much easier. In one hour, perhaps five or six pollen grains or fruits can be examined and photographed. This is valuable for people such as Professor Heywood and his team at the University of Liverpool. They are conducting a taxonomic study of the tribe Caucalidac of the Umbelliferae, and are collecting characters from as many parts of the plant as possible. When examining the fruits for distinguishing characters, and having found morc than forty with little effort, the team began to use the scanning electron microscope. This is revealing many

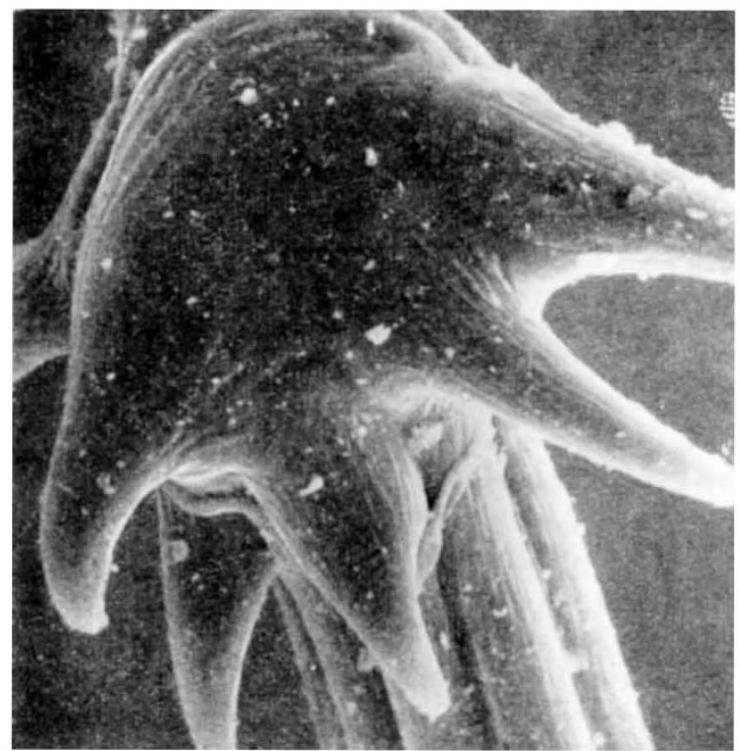

The apex of a main spine on the fruit of Torilis leptophylla $(\times 1,250)$.

features of the ridges, hairs and spines of fruits which were previously not seen, or were seen but not understood. These are features such as the apex of the spine on the fruit of Torilis leptophylla which is shown in the photograph. Turgenia latifolia, for example, has revealed surface projections on the fruit which are unique to the species.

Now that taxonomists are finding more characters than ever before, they have the problem of handling all this information. To begin with, a new terminology is needed to describe the surface features of the fruits, seeds or pollen grains. Methods of scoring and processing the data which are being so effectively recorded have also to be developed before the full value of the new techniques can be appreciated.

\section{Elementary Genetic Control}

\section{from a Correspondent in Cell Biology}

FACTORS which control gene activity of necessity control development. They are elusive, but there are indica. tions that the control of some chromosomal genes is the product of some structural feature of the chromosome itself. There is one well known example-in female mammalian cells genes on one of the two $X$ chromosomes are inactivated because one of the chromosomes becomes condensed or heterochromatic. Whether the paternal or maternal $X$ chromosome is inactivated in this way is a matter of chance.

This process of inactivation has been explored by Cattenach and Isaacson (Genetics, 5\%, 331; 1967). In 1965 Cattenach showed that when part of the autosome carrying some of the genes controlling coat colour is inserted into one of the $X$ chromosomes $\left(X^{T}\right)$, these genes may be inactivated, but to a variable degrec. One result is that two lines of mice with distinctive coat colour patterns can be selected and the stability of the inactivation studied directly by breeding experiments. In practice the inactivation of $X^{T}$ is found to change on passage through several generations. Cattenach and Isaacson account for this change in the state of gene activity by proposing that there is a "controlling element" on the $X$ chromosome which 